\title{
Discursos de instituições de saúde brasileiras sobre atividade física no início da pandemia de COVID-19
}

\section{Discourses of Brazilian health institutions on physical activity at the beginning of the COVID-19 pandemic}

\section{AUTORES \\ Alan Goularte Knuth ${ }^{1,2}$ (D) \\ Fabio Fortunato Brasil de Carvalho ${ }^{3}$ \\ Débora Duarte Freitas ${ }^{4}$ (D) \\ 1 Universidade Federal do Rio Grande. Instituto de Educação. Programa de Pós-graduação em Saúde Pública. Rio Grande, Rio Grande do Sul, Brasil. 2 Universidade Federal de Pelotas. Programa de Pós-graduacão em Educação Física. Pelotas, Rio Grande do Sul, Brasil. \\ 3 Instituto Nacional de Câncer José Alencar Gomes da Silva (INCA) / Ministério da Saúde. Rio de Janeiro, Rio de Janeiro, Brasil. \\ 4 Instituto Federal Farroupilha. Campus Avancado Uruguaiana. Uruguaiana, Rio Grande do Sul, Brasil.}

\section{CONTATO}

Alan G. Knuth

alan_knuth@yahoo.com.br

Av. Itália, s/n - Km 8 - Carreiros, Rio

Grande, Rio Grande do Sul, Brasil.

Cep. $96203-900$

DOI

$10.12820 /$ rbafs. $25 \mathrm{e} 0122$

\section{(cc) BY}

Este trabalho está licenciado com uma Licença Creative Commons - Atribuição 4.0 Internacional.

\begin{abstract}
RESUMO
Este estudo objetiva analisar os discursos produzidos por instituições de saúde sobre atividade física no início da pandemia de COVID-19 (março e começo de abril) no Brasil. Foi realizado um estudo documental a partir de sites de instituições de saúde, com o aporte teórico-metodológico inspirado nos estudos foucaultianos a partir do entrelaçamento da noção de discurso e seu impacto no governo das condutas. Foram compiladas 17 comunicações, sendo três de instituições governamentais, nove de sociedades médicas e cinco da educação física. Os primeiros comunicados abordaram a higiene pessoal e de equipamentos, referentes a locais fechados e em seguida a restrição de atividade física em tais espaços, indicando o domicílio para a realização das práticas. Assim, houve predomínio da atividade física em sua vertente biológica especialmente na estimativa de afetar a função imunológica. Problematizamos os discursos a partir da noção do governo das condutas, onde indivíduos e famílias foram acionados a praticar atividade física em casa, sem garantia de instrumentalização e acesso ao conhecimento e profissionais desta área.
\end{abstract}

Palavras-chave: Pandemias; Comunicação em saúde; Atividade motora; Discurso.

ABSTRACT

The aim of this article is to analyze discourses produced by health institutions regarding physical activity in the beginning of the COVID-19 pandemic (March and early April) in Brazil. A documentary study was carried out using websites of health institutions. The process were theoretical-methodological support inspired in Foucault's studies based on the intertwining notion of discourse and its impact on the conduct of the government. A total of 17 documents were compiled, three from government institutions, nine from medical societies and five from physical education institutions. The first documents addressed the personal and equipment hygiene concerning closed places, the following communications were about restricting physical activities in these places, finally recommending the performance of these activities at home. Therefore, physical activity predominated in its biological perspective, especially affecting immune function. The problematization of the discourses was carried out based on the governmentality notion in which individuals and families were triggered to practice physical activities at home without instrumentalization, access to knowledge and to physical education professionals.

Keywords: Pandemics; Health communication; Motor activity; Discourse.

\section{Introdução}

Desde 31 de dezembro de 2019 a partir da cidade de Wuhan na China, o campo da saúde passou a lidar com a descrição de um novo coronavírus, caracterizado como SARS-CoV-2. Este vírus foi ligado a uma nova doença respiratória, intitulada COVID-19, a qual foi classificada como Pandemia pela Organização Mundial da Saúde (OMS) em 11 de março de 20201.

Prontamente as principais medidas de prevenção foram amplamente comunicadas e incluem: lavar as mãos com água e sabão ou usar álcool gel, cobrir nariz e boca ao tossir e espirrar, evitar aglomerações, manter os ambientes bem ventilados, evitar tocar olhos, nariz e boca com as mãos, dentre outras².

No Brasil, o primeiro caso foi confirmado no final de fevereiro, inaugurando a doença na América Latina, ainda que estudos retrospectivos sigam atualizando a precisão dos primeiros casos. Em seguida, diversos fatos se sucederam e entre estes, boa parte dos estados e municípios induziram medidas de restrição da circulação e aglomeração decretando interrupção de aulas, direcionamento para trabalho em casa e de forma remota, diminuição dos transportes, restrição de atividades comerciais, no sentido de promover distanciamento social.

Uma campanha caracterizada como "fique em casa" se intensificou desde 16 de março de $2020^{3}$. Os 
principais argumentos para tais decisões foram: frear o espalhamento dos casos, preparar serviços de saúde para o enfrentamento da doença, evitar muitos casos ao mesmo tempo e ainda uma corrida por equipamentos de proteção, testes de detecção e cuidados com os profissionais de saúde. Em poucos dias as comunicações oficiais do Ministério da Saúde, da OMS, demais instituições de saúde, grande mídia e redes sociais on-line traziam a doença para a centralidade da vida de todos.

Nesta esteira, ampliaram-se as abordagens e recomendações às pessoas que podiam ficar em casa. Dentre as estratégias, o estímulo à atividade física foi bastante acionado, conforme o próprio site do Ministério da Saúde que a elencou como medida de proteção, a saber: "durma bem, tenha uma alimentação saudável e faça atividade física"4.

A atividade física é um tema que figura nas políticas de saúde há, pelo menos, duas décadas. O tema é reconhecido como fator de proteção para diversas condições de saúde, especialmente no quadro das doenças crônico-degenerativas ${ }^{5}$. Debates teórico-metodológicos buscam consistência no eixo Atividade Física/Práticas Corporais, muitas vezes tentando desviar do tom medicalizado que o tema assumiu no campo da saúde, a partir da predominância do discurso epidemiológico associado ao risco. Ao buscar superar a perspectiva exclusivamente biomédica, consideram-se outras questões como os condicionantes e determinantes dos processos de saúde/doença e com isso as contribuições das ciências sociais e humanas tornam-se essenciais ao entorno da atividade física.

As recomendações de praticar atividade física nos domicílios ocorreram muito em função do fechamento de parques, academias, centros de treinamento físico e programas públicos associados durante a experiência brasileira na pandemia, pelos decretos já citados em diferentes estados e municípios.

Um dos efeitos da pandemia, que se relaciona com o distanciamento social e a atividade física, foi a emissão de comunicados por instituições de saúde, alcançando as diversas esferas sociais produzindo e reproduzindo sentidos para esta prática, especialmente no início da pandemia. As instituições de saúde têm uma importância histórica ao congregar profissionais de saúde, elaborar posicionamentos, contribuir com os processos decisórios e influenciar as pautas de saúde juntamente aos profissionais e à população por diferentes meios de comunicação, dentre eles os veículos midiáticos.

A partir daí, o objetivo do presente artigo foi ana- lisar os discursos produzidos por instituições de saúde sobre atividade física no início da pandemia de COVID-19, no Brasil em 2020.

\section{Métodos}

Trata-se de um estudo documental em que a internet foi a base de informações. $\mathrm{O}$ disparador da pesquisa foi a pandemia de COVID-19 e as particularidades relacionadas à atividade física, no período inicial: março e início de abril de 2020. A presente pesquisa está dispensada de tramitação ética no sistema CEP/CONEP por utilizar informações de domínio público.

As buscas de informações iniciaram em $1^{\circ}$ de abril de 2020, quando o Brasil apresentava 6.836 casos confirmados e 241 óbitos por COVID-196. Conforme os pressupostos de Fragoso, Recuero e $\mathrm{Amaral}^{7}$ a pesquisa se baseou em dados públicos, amplamente dispostos na internet, não sendo necessária vinculação com as instituições pesquisadas.

A busca inicial e exploratória foi realizada de forma independente por dois pesquisadores e revisada por uma terceira, já na etapa de análise a partir do que fora levantado na fase exploratória. Não partiu-se de categorias a priori, portanto os documentos foram lidos na íntegra para conhecimento dos discursos, sem empregar uma análise quantitativa. Todos trabalharam de suas casas em período de distanciamento social. Para identificar os comunicados nos sites das instituições de saúde, conforme a intencionalidade dos autores ${ }^{8}$, foram checados diretamente alguns sites de instituições de saúde e perfis em redes sociais on-line que direcionassem aos sites oficiais, para rastreamento das comunicações.

Os seguintes critérios foram elencados para se chegar ao material de análise:

a) Publicações disponíveis a partir da decretação de pandemia de COVID-19 pela OMS em 11 de março de 2020 até a finalização da coleta em 03 de abril de 2020; ou seja, o presente artigo cobre a fase inicial da pandemia no Brasil e a discussão que envolve a atividade física nesse período;

b) Publicações de instituições de saúde brasileiras em seus sites oficiais;

c) Publicações que se referissem diretamente a "Atividade Física", "Exercício Físico" e "Práticas Corporais".

Tratou-se como instituição de saúde toda sociedade, entidade, grupo organizado que ao comunicar sobre as questões do campo da saúde encontraria ampla re- 
percussão ou, ainda, que tenha um grupo de trabalho específico com relação ao tema da atividade física e saúde, o qual assine os comunicados.

Como critérios de exclusão aparecem as normativas como leis e decretos, das esferas municipal, estadual e federal versando ou não sobre atividade física e pandemia, as comunicações individuais de profissionais sem a chancela das instituições, conteúdos originados do sistema de educação, ainda que de grupo de pesquisa ou coletivos relacionados à saúde ou atividade física. Também não foram consideradas postagens exclusivas de redes sociais on-line.

A análise dos materiais foi realizada a partir da leitura e sistematização de cada documento, onde caracterizou-se a data, tipo de instituição e site, formato do comunicado e principais aspectos de conteúdo.

$\mathrm{O}$ aporte teórico-metodológico, de inspiração foucaultiana, aborda as estratégias de governo das condutas acionadas pelos discursos de incentivo à prática de atividade física. Os autores se utilizam do deslocamento teórico do autor da fase ser-poder (genealógica) para o ser-consigo (ética) para explorar esse conjunto de regras anônimas e históricas, determinadas dentro de um tempo e espaço. Nesse sentido, os discursos de instituições de saúde podem ser tomados como práticas, que estão imersas em relações de poder e saber, com implicações mútuas ${ }^{8}$, dentro da racionalidade política e econômica em que vivemos.

A partir do desbloqueio das artes de governar, em meados do século XVI, que são dadas as condições de possibilidades para a entrada da vida nas relações de poder-saber; nesse momento é que a vida humana se torna passível de intervenção. Mediante a solidificação de um biopoder, em especial da biopolítica, percebe-se deslocamentos nas tecnologias de poder e uma inversão da máxima do "fazer morrer, deixar viver" para ações que se concentrem em "fazer viver, deixar morrer" 9

Assim, passamos a uma relação de poder-saber que visa a manutenção da vida, mediante ações direcionadas para a condução da conduta onde são colocadas em prática estratégias sobre o conjunto das ações humanas ${ }^{10}$. Essas permitem as condições para que o discurso da atividade física seja divulgado e disseminado como uma ferramenta importante em favor da vida, pela noção foucaultiana empregada.

Nesse sentido, objetiva-se dar visibilidade às estratégias de governamento postas em funcionamento nos discursos analisados e que objetivam nos conduzir a um modo de vida considerado como válido e ideal.
Dessa forma, pesquisar nessa perspectiva "seria, consideravelmente, habitar incertezas e estranhar o familiar" trata-se, sobretudo, de assumir uma postura crítica ao que está dado.

\section{Resultados}

Foram localizadas 17 comunicações de instituições de saúde que envolviam a atividade física, em seis notas, três informes, cinco notícias, duas publicações e uma moção de repúdio. Destas, 03 oriundas de instituições governamentais, 09 de sociedades e associações médicas, 04 de conselhos profissionais da Educação Física e 01 de instituição científica da Educação Física.

Ainda que algumas instituições utilizem a terminologia do exercício físico ou raramente das práticas corporais, a predominância de utilização é pela atividade física, opção reproduzida no presente artigo.

Encontra-se com repetição nos discursos uma dupla argumentação pela atividade física na perspectiva biológica: a) a relação com a melhora da função imunológica, em termos gerais e para todas as pessoas; b) a proteção que a prática traria na prevenção e tratamento de doenças crônico-degenerativas, onde uma grande parte das pessoas dos grupos de risco para casos graves da COVID-19 está colocada, especialmente os idosos.

Também foram tratados frequentemente os seguintes conteúdos: exemplos de práticas de atividade física para realizar em casa, orientações para o cuidado com higiene de equipamentos e materiais utilizados durante a atividade física, diversas indicações de não praticar atividade física em ambientes fechados ou com aglomeração de pessoas. Os comunicados dos conselhos profissionais estabeleceram sugestões aos profissionais e proprietários de estabelecimentos, principalmente as academias de ginástica e recomendaram às pessoas que buscassem profissionais da área.

Por fim, uma manifestação de contrariedade em relação a um discurso oficial do Presidente da República que tentou amenizar a gravidade da COVID-19. As fontes utilizadas neste trabalho estão esmiuçadas no quadro 1 (instituição, endereço de link visitado, data de publicação, tipo de comunicado e sumário do que fora encontrado).

Mesmo que não se tenha empreendido uma análise quantitativa sobre os discursos, pode-se registrar que a perspectiva biológica da atividade física aparece em, pelo menos, 10 comunicados. E três temas aparecem em quatro deles: a recomendação de evitar ambientes fechados ou de praticar ao ar livre; os cuidados de higiene com equipamentos; e exemplos de atividade físicas. 
Em síntese, a compilação dos comunicados pode ser descrita em duas fases. A fase inicial logo após a decretação de pandemia, onde os cuidados estavam voltados à higiene pessoal e de equipamentos, além de cuidados para não aglomeração em locais fechados com atividade física. Uma segunda fase foi observada quando gra- dativamente, por efeito de decretos da esfera executiva, se recomendou a restrição de práticas em locais fechados, a prática de atividade física em casa, excepcionalmente ao ar livre de forma individual e por último a indicação de atividades somente em casa, em cidades e estados com decreto oficial de distanciamento social.

Quadro 1 - Compilado dos comunicados das instituições brasileiras de saúde sobre atividade física e a pandemia de COVID-19.11 de Março a 3 de Abril de 2020.

\begin{tabular}{|c|c|c|c|}
\hline Instituição e link pesquisado & Data & Tipo & Conteúdos dos comunicados \\
\hline \multicolumn{4}{|l|}{ Instituições governamentais } \\
\hline \multirow{3}{*}{$\begin{array}{l}\text { Ministério da Saúde (MS) } \\
\text { https://saudebrasil.saude.gov.br/eu-quero-me-exercitar- } \\
\text { mais/diario-de-uma-pandemia-5-dicas-para-orientar- } \\
\text { pais-e-criancas } \\
\text { https://www.inca.gov.br/publicacoes/material-para-web/ } \\
\text { por-que-e-importante-manter-se-fisicamente-ativo- } \\
\text { durante-pandemia-de } \\
\text { https://www.inca.gov.br/publicacoes/material-para-web/ } \\
\text { atividades-fisicas-que-voce-pode-fazer-em-casa }\end{array}$} & $1^{\circ}$ de abril & Notícia & $\begin{array}{l}\text { Dá dicas a pais e crianças com enfoque no brincar, jogar, } \\
\text { dançar, tentando diminuir o foco dos eletrônicos. Também } \\
\text { sugere Yoga, além de abordar pequenas tarefas domésticas } \\
\text { como organizar e limpar o próprio quarto e os brinquedos, } \\
\text { jardinagem ou varrer algum cômodo. }\end{array}$ \\
\hline & 03 de abril & Publicações & $\begin{array}{l}\text { Em formato de card, busca responder por que é } \\
\text { importante manter-se fisicamente ativo, desde o controle } \\
\text { de doenças crônicas, saúde mental, prazer e relaxamento e } \\
\text { o fortalecimento do sistema imunológico }\end{array}$ \\
\hline & 03 de abril & Publicações & $\begin{array}{l}\text { Em formato de card, fornece exemplos de atividades } \\
\text { físicas que podem ser realizadas no ambiente doméstico, } \\
\text { como dançar, varrer, caminhar e subir e descer escadas. }\end{array}$ \\
\hline \multicolumn{4}{|l|}{ Sociedades e Associações médicas } \\
\hline \multirow[t]{5}{*}{$\begin{array}{l}\text { Sociedade Brasileira de Medicina do Exercício e do } \\
\text { Esporte (SBMEE) } \\
\text { http://www.medicinadoesporte.org.br/informes-da- } \\
\text { sbmee-sobre-coronavirus-e-exercicio-fisico/ }\end{array}$} & 17 de março & Informe & $\begin{array}{l}\text { Descreve o papel do exercício físico na função } \\
\text { imunológica, proteção contra doenças crônicas que seriam } \\
\text { grupos de risco na COVID-19, evitar locais fechados, } \\
\text { exercícios ao ar livre devem evitar contato com outras } \\
\text { pessoas }\end{array}$ \\
\hline & 19 de março & Informe 2 & $\begin{array}{l}\text { Orienta que pacientes com doenças crônicas devem evitar } \\
\text { ida ao local de prática. Devem adaptar os exercícios para } \\
\text { o ambiente domiciliar ou atividades ao ar livre, evitando } \\
\text { os grupos }\end{array}$ \\
\hline & 22 de março & Nota & $\begin{array}{l}\text { Sugere que exercícios não devem ser realizados ao ar livre, } \\
\text { indicando a realização da prática em casa, nos lugares } \\
\text { onde a quarentena tenha sido decretada }\end{array}$ \\
\hline & 25 de março & Nota & $\begin{array}{l}\text { Adverte para o caráter dinâmico das atualizações e reforça } \\
\text { a recomendação de não praticar exercícios ao ar livre, } \\
\text { citando medida de restrição do Estado de São Paulo }\end{array}$ \\
\hline & 30 de março & Informe 3 & Responde perguntas mais frequentes \\
\hline $\begin{array}{l}\text { Sociedade Brasileira de Endocrinologia e Metabologia } \\
\text { (SBEM) } \\
\text { https://www.endocrino.org.br/exercicio-fisico-na- } \\
\text { quarentena/ }\end{array}$ & 27 de março & Notícia & $\begin{array}{l}\text { Descreve em forma de itens: exercício como reforço para a } \\
\text { imunidade, higiene com os materiais esportivos usados no } \\
\text { exercício, como fones e celulares }\end{array}$ \\
\hline $\begin{array}{l}\text { Sociedade Brasileira de Cardiologia (SBC) } \\
\text { https://www.portal.cardiol.br/post/atividade- } \\
\text { f\%C3\%ADsica-durante-a-pandemia-de- } \\
\text { coronav\%C3\%ADrus }\end{array}$ & $1^{\circ}$ de abril & Notícia & $\begin{array}{l}\text { Trata de uma rotina fisicamente ativa. Diferencia atividade } \\
\text { física de exercício físico. Recomenda algumas atividades } \\
\text { físicas e cita a atenção com os filhos, para tirá-los do } \\
\text { tempo sedentário. A prática deve ser abandonada se } \\
\text { apresentar sintomas de COVID-19 }\end{array}$ \\
\hline $\begin{array}{l}\text { Sociedade Brasileira de Diabetes (SBD) } \\
\text { https://www.diabetes.org.br/covid-19/pratica-de- } \\
\text { atividade-fisica-durante-o-distanciamento-social/ }\end{array}$ & $\begin{array}{l}\text { Sem data } \\
\text { especificada }\end{array}$ & Notícia & $\begin{array}{l}\text { Detalha o caso do diabetes. Aponta o efeito da atividade } \\
\text { física na ansiedade e imunidade. Dá exemplos de exercícios } \\
\text { e alerta a necessidade de checar as qualificações do } \\
\text { profissional/aplicativo já que há grande oferta desses serviços. }\end{array}$ \\
\hline $\begin{array}{l}\text { SBEM, SBD, SBMEE e Associação Brasileira } \\
\text { de Estudo da Obesidade e Síndrome Metabólica } \\
\text { (ABESO) } \\
\text { https://www.diabetes.org.br/publico/images/4- } \\
\text { sociedades-medicas-contra-o-coronavirus.pdf }\end{array}$ & 21 de março & $\begin{array}{l}\text { Nota } \\
\text { Conjunta }\end{array}$ & $\begin{array}{l}\text { Pessoas ativas têm menor chance de apresentar doenças } \\
\text { crônico-degenerativas que levam seus portadores a serem } \\
\text { considerados de maior risco para a o coronavírus. Indicam } \\
\text { que exercícios muito intensos não devam ser escolhidos } \\
\text { agora pela sua função imunossupressora. }\end{array}$ \\
\hline
\end{tabular}




\begin{tabular}{|c|c|c|c|}
\hline Instituição e link pesquisado & Data & Tipo & Conteúdos dos comunicados \\
\hline \multicolumn{4}{|l|}{ Conselhos profissionais } \\
\hline $\begin{array}{l}\text { Conselho Federal de Educação Física (CONFEF) } \\
\text { https://www.confef.org.br/confef/comunicacao/ } \\
\text { noticias/1475 }\end{array}$ & 17 de março & Notícia & $\begin{array}{l}\text { Comunicado aos profissionais. Sugere que grupos de risco } \\
\text { treinem em casa, manter equipamentos higienizados e } \\
\text { ambientes arejados, disponibilizar material de higiene } \\
\text { nos locais de prática, não programar eventos com } \\
\text { aglomerações, }\end{array}$ \\
\hline $\begin{array}{l}\text { Conselho Regional de Educação Física (CREF3/SC) } \\
\text { https://www.crefsc.org.br/cref3sc-divulga-nota-sobre- } \\
\text { pratica-de-atividade-fisica-e-o-coronavirus-covid-19/ }\end{array}$ & 25 de março & Nota & $\begin{array}{l}\text { Orienta a não realizar atividade física ao ar livre e sim } \\
\text { nas residências. Sugere a orientação com profissionais } \\
\text { registrados. Trata dos benefícios imunológicos, doenças } \\
\text { crônicas e os idosos. Orienta profissionais a terem } \\
\text { cuidados com vídeos de treinos para serem realizados em } \\
\text { casa, cuidando de certas especificidades }\end{array}$ \\
\hline $\begin{array}{l}\text { Conselho Regional de Educação Física (CREF4/SP) } \\
\text { http://www.crefsp.gov.br/noticia/16330-COVID-19:- } \\
\text { NOTA-DE-ESCLARECIMENTO-N\%C2\%B0-1 }\end{array}$ & 18 de março & Nota & $\begin{array}{l}\text { Dispõe de orientações para escolas e academias de cidades } \\
\text { que não tenham decretos específicos de fechamento, } \\
\text { sugerindo diminuição do contato, maior higiene, atenção a } \\
\text { grupos de risco. Menciona a adoção de medidas de pressão } \\
\text { para garantia de empregos da área profissional }\end{array}$ \\
\hline $\begin{array}{l}\text { Conselho Regional de Educação Física - CREF1/ } \\
\text { RJ-ES } \\
\text { https://cref1.org.br/informe/nota-tecnica-do-cref1- } \\
\text { sobre-o-coronavirus/ }\end{array}$ & 15 de março & Nota & $\begin{array}{l}\text { Recomenda que idosos fiquem em casa. Sugere que as } \\
\text { academias tenham cuidado na higienização dos ambientes, } \\
\text { aparelhos e também que procurem medidas para aumentar } \\
\text { o isolamento entre alunos. Suspendem atividades com } \\
\text { maior aglomeração }\end{array}$ \\
\hline \multicolumn{4}{|l|}{ Instituição científica da Educação Física } \\
\hline $\begin{array}{l}\text { Colégio Brasileiro de Ciências do Esporte (CBCE) } \\
\text { http://www.cbce.org.br/noticias-detalhe.php?id=1435 }\end{array}$ & 25 de março & $\begin{array}{l}\text { Moção de } \\
\text { repúdio }\end{array}$ & $\begin{array}{l}\text { Analisa criticamente a fala do Presidente da República, } \\
\text { Jair Messias Bolsonaro, relacionada ao menor risco de } \\
\text { agravamento do quadro de Covid-19 pelo "histórico de } \\
\text { atleta". Avalia que não há evidências do histórico reduzir } \\
\text { seus riscos de contágio. Defende ainda que exercícios } \\
\text { físicos não são "remédios" ou "vacinas" }\end{array}$ \\
\hline
\end{tabular}

\section{Discussão}

A prática de atividade física durante o distanciamento social provocado pela pandemia de Covid-19 é tratada como importante entre diferentes instituições ${ }^{12-14}$. Segundo Chen et al. ${ }^{15}$ medidas oficiais que restringem a circulação das pessoas não significam necessariamente que a atividade física deva ser limitada ou que todas as suas formas devam ser eliminadas.

Contudo, é de se destacar que na fase inicial, em março, as possibilidades de utilização de academias e locais semelhantes ainda perdurou mesmo com o aumento exponencial de casos e óbitos. Em alguns estados, nos quais houve posicionamento, os Conselhos profissionais possivelmente priorizaram questões corporativistas e menos o cuidado e precaução com as populações. Por exemplo, quando recomendavam uma determinada distância entre os praticantes e uma frequência de higienização de aparelhos e implementos pouco usuais nos ambientes de academia ${ }^{16,17}$.

Cabe ressaltar que não se trata de afirmar se a população deve ou não fazer atividade física, tampouco para manifestar-se contra ou a favor dos documentos analisados; para além do 'bem e do mal', propõe-se compreender os discursos como uma construção social que põe em funcionamento estratégias de condução da conduta que se utilizam de um status de verdade para atingirem seus objetivos.

Argumenta-se que as reincidências discursivas sobre a atividade física se encontram inscritas em uma grade de inteligibilidade de nosso tempo que, articulada a princípios de mercado, necessita de sujeitos capazes de autogoverno que, por meio de disseminação das informações, se conduziriam adequadamente e contribuiriam para alcançar determinados objetivos. As práticas discursivas parecem se direcionar à população como um todo nos comunicados do Ministério da Saúde e entidades médicas, por exemplo:

"Antes de mais nada, todos em casa, certo? Depois disso, hora de pensar em como se movimentar em um período tão delicado, a quarentena." (SBEM)

E também:

"Para ajudar nessa missão, vamos sugerir algumas atividades para distrair as crianças quando elas estiverem em casa" (Ministério da Saúde). 
De maneira geral, os discursos são direcionados à população leiga, em especial no nível individual ou para as famílias. Destacamos a reincidência discursiva em relação à prática de atividade física num sentido biológico e determinístico, conforme seguem:

"Brincar, jogar, dançar e se divertir fazem bem para a saúde e entretêm as crianças. Mais do que nunca, é hora de tirar o foco dos eletrônicos e colocar o corpo em movimento" (Ministério da Saúde).

"Pessoas ativas fisicamente têm menor chance de apresentar doenças como diabetes, obesidade, hipertensão, doenças cardiovasculares e outras patologias crônico-degenerativas que levam portadores a serem considerados de maior risco para infeç̧ão pelo novo coronavirus" (SBEM).

"Se exercitar é um excelente "remédio" não só para o corpo, mas também para a mente" (SBC).

Conforme foi apontado, em relação aos benefícios da atividade física no controle das doenças crônicas, há importantes evidências ${ }^{5}$, mas sobre o sistema imune, é importante ressaltar que as respostas são diferenciadas em agudas e crônicas, dependem do tipo de atividade física, da duração e intensidade, do condicionamento físico e das condições de saúde da pessoa, além de outros fatores, inclusive podendo ter efeitos deletérios quando extenuantes ${ }^{18,19}$.

Assim, tratada de forma dada e simples, a relação da atividade física com a imunidade também está impregnada de incertezas e complexidades, algo pouco ou nada tratado nas estratégias discursivas. Ainda que haja o reconhecimento de que a forma da comunicação pode limitar os sentidos, é possível afirmar que há uma idealização da atividade física como simplória na maioria dos documentos, desconsiderando a complexidade que pode assumir ${ }^{20,21}$

Dentre os documentos analisados está uma moção de repúdio ${ }^{22}$. Os autores se posicionam que o "exercício físico” não é sinônimo de 'remédio' ou de 'vacina' e que não deveria ser utilizado com tal propósito, "fazendo a população acreditar que poderia ser salva de diferentes doenças". A moção foi uma resposta direta a um pronunciamento do Presidente da República Jair Messias Bolsonaro, no texto critica-se exatamente o tipo de discurso que coloca na atividade física a garantia de uma vida saudável. Foi o único comunicado apresentando contrapontos sobre a relação atividade física e saúde.

Destaca-se o fato de que em apenas quatro comunicados há apontamentos sobre o que praticar de atividade física, contudo acreditamos que de forma insuficiente, pois carecem de diversificação, adaptação das práticas às diferentes realidades sociais, gêneros, conhecimento e experiência, acesso a profissionais, pois estes e outros aspectos dizem muito da complexidade envolvida com a atividade física. Os discursos analisados parecem pressupor que a população já sabe o que fazer e que só precisariam ser estimuladas a iniciarem ou mesmo que todos vivem sob as mesmas condições. As manifestações analisadas passam orientações amplas e generalizadas à população, colocando no indivíduo, possivelmente leigo e, muitas vezes, desorientado pela proliferação discursiva acerca da COVID-19, a responsabilidade de tomar a decisão (adequada) sobre a sua vida. Diante da novidade e dinamicidade da pandemia, suas exigências e restrições, os próprios profissionais podiam estar em situações de desconhecimento sobre como conduzir as ações de atividade física. Considerando os próprios dados epidemiológicos brasilei$\operatorname{ros}^{23}$ é de se supor que grande parte da população não tenha acesso e/ou não pratique atividade física, especialmente de lazer e, portanto, é uma prática que pode ser pouco usual ao cotidiano das pessoas, em termos de conhecimento e vivência.

Esse direcionamento ao indivíduo parece estar localizado em uma grade de inteligibilidade de nosso tempo, que se encontra pautada em princípios de mercado. Atualmente, não há uma separação entre mercado e Estado e sim uma justaposição. Logo, no neoliberalismo, o mercado já absorveu o Estado, por isso o Governo "deve acompanhar de ponta a ponta uma economia de mercado. A economia do mercado não subtrai algo do governo. Ao contrário, ela indica, ela constitui o indexador geral sob o qual se deve colocar a regra que vai definir todas as açôes governamentais" ${ }^{10}$.

Chignola ${ }^{24}$ afirma que no neoliberalismo o problema "é o 'governo' de um sujeito que deve ser deixado livre para agir para que possam se desenvolver as dinâmicas de mercado" (p. 22). Tal racionalidade necessita de sujeitos autônomos, autoempreendedores, capazes de autogoverno. É neste sentido que Chignola ${ }^{24}$ destaca que

As políticas de saúde, por exemplo, trabalham cada vez mais com "conselhos" que visam à responsabilização do indivíduo (não fumar, submeter-se a exames regulares, seguir uma dieta...) para a obtenção de efeitos gerais. 
O que anteriormente estava sob a tutela das instituições, como a saúde pública, agora é de responsabilidade individual. E o indivíduo governado pela sua autopercepção é considerado uma pessoa madura, responsável, solidária (p. 23).

Nesse sentido, a responsabilização pelo sucesso ou fracasso sobre suas condições de saúde está direcionada fortemente ao indivíduo, retirando de maneira cada vez mais intensa a responsabilidade do Estado. Nesse tipo de sociedade "sujeitos com direitos são obrigados a ser livres, isto é, fazer opçóes dentro de um Estado limitado onde - bem-estar é reduzido ou modificado a cada viravolta do mercado"25.

Esse tipo de racionalidade coloca sobre os sujeitos toda e qualquer escolha executada, visto que com a liberdade proporcionada cabe ao indivíduo tomar as decisões e assumir, por consequência, a responsabilidade sobre seus triunfos ou insucessos. Estudos que avaliam certos programas de atividade física já o analisaram enquanto dispositivo biopolítico da atualidade, investindo nos modos de viver e adotando tom conservador, culpabilizando os indivíduos não atraídos pelo tema da atividade física ${ }^{26}$.

Dentro desta lógica de pensamento é muito mais comum ater-se a movimentos que focam no indivíduo do que sobre demandas que exijam ações governamentais. Como na lógica neoliberal o mercado comanda, é necessário fazer mais com o mínimo de investimento, isto é, ao invés de perceber a atividade física no seu contexto multifatorial, são orientadas ações para o indivíduo pautadas em critérios de eficácia e otimização, isso é, biológicos e tecnicistas, desconsiderando inúmeras variáveis que devem ser consideradas em um elemento da vida humana que é multifatorial e de alta complexidade. O discurso assumido pela área da atividade física poderá ser reprodutor desta lógica ou buscar desestabilizações que apontem as dificuldades de praticar atividade física e buscar os sentidos vivenciados pela população.

A produção do discurso em uma sociedade "é ao mesmo tempo controlada, selecionada, organizada e redistribuida por certo número de procedimentos que têm por função conjurar seus poderes e perigos, dominar seu acontecimento aleatório, esquivar sua pesada e temivel materialidade"27. Toda relação de saber estabelece uma relação de poder e por isso os discursos têm papel fundamental na maneira que produzimos e conduzimos os modos de vida hoje.
É o jogo entre poder-saber-verdade que estabelece, a cada época, determinados regimes discursivos que constrangem os indivíduos a modos específicos de ação. Nesse sentido, Foucault ${ }^{28}$ afirma que "não pode haver governo sem que os que governam indexem suas ações, suas opções, suas decisões a um conjunto de conhecimentos verdadeiros". No entanto, atenta-se ao fato de que hoje "mais do que nunca, tudo parece levar-nos a afirmar que uma compreensão do conceito de saúde depende de parâmetros cientificos e claramente estabelecidos", mas que talvez "descubramos que estas politicas estão mais próximas das estratégias de mercado do que dos efetivos programas de promoção da saúde" 29.

A partir dos discursos apresentados no presente texto, questiona-se: quais seriam os impactos de iniciar a prática de atividade física nesse momento pandêmico para a população brasileira? Em uma crise de saúde como essa, quais são as contribuições para saúde que vão além de marcadores biológicos individuais que contribuem para o controle das doenças crônicas?

A intenção não é necessariamente responder a tais questionamentos, mas problematizarmos a proliferação discursiva acerca da atividade física que se coloca nesse momento pandêmico e pode ser explorada em futuras análises, especialmente pela extensão da experiência com a doença e a sequência de debates com a atividade física, como na questão das academias de ginástica como serviços essenciais e sua reabertura, análise pertinente, mas fora do escopo do trabalho.

Em um momento de incertezas e de mudanças forçadas nas rotinas, a atividade física deve ser vista como uma opção e não como mais uma atribuição obrigatória na produção de saúde ou ainda para preencher o dia a partir de uma ideia de produtividade em oposição ao ócio de ficar em casa, especialmente se considerar que não houve tempo e condições de estabelecer relação científica da atividade física com a COVID-19.

Ainda que haja a defesa, por parte dos autores deste manuscrito, de princípios da Promoção da Saúde, como autonomia e empoderamento ${ }^{30}$, é inegável que os discursos possuem determinadas intencionalidades e há formas muito distintas de compreensões e recepção deles no cotidiano de vida das pessoas. A prática de atividade física ainda se dá de forma desigual no país e, muitas vezes, inscrita em uma lógica neoliberal e regida por princípios de mercado que recorrentemente não priorizam a vida ou à saúde.

Conclui-se que a atividade física foi bastante acionada discursivamente por entidades públicas, médicas e 
corporativas durante a pandemia de COVID-19, com a produção de 17 comunicados entre março e abril. Houve controvérsia em parte dos discursos, mas predomínio da defesa da atividade física por sua resposta biológica. Problematizamos os discursos colocados em prática pelas instituições de saúde, dando visibilidade para a forma contemporânea de governo das condutas, que acionam indivíduos e famílias a praticar atividade física em casa, sem maior instrumentalização e sem garantia de acesso ao conhecimento e profissionais da área, fortalecendo uma lógica de mercado que coloca sob o indivíduo a responsabilidade sobre sua saúde desconsiderando, muitas vezes, condições socio-econômico-culturais da população.

No momento de realização da análise e finalização do manuscrito não havia indícios que a pandemia estaria perto de ser controlada, assim é esperado que novos acontecimentos relacionados à atividade física ocorram no decorrer da pandemia, ensejando novas análises desse complexo fenômeno.

\section{Conflito de interesses}

Os autores declaram não haver conflito de interesses.

\section{Contribuições dos autores}

Knuth AG foi responsável pela concepção inicial do estudo e Knuth AG, Carvalho FFB e Freitas DD participaram da redação e revisão crítica do texto.

\section{Referências}

1. World Health Organization/WHO. WHO DirectorGeneral's opening remarks at the media briefing on COVID-19 - 11 March 2020. 2020. [citado em 2020 mar 28]. Disponível em: https://www.who.int/dg/speeches/ detail/who-director-general-s-opening-remarks-atthemedia-briefing-on-covid-19-11-march-2020.

2. Brasil. Ministério da Saúde. notícias. Saúde anuncia orientações para evitar a disseminação do coronavírus. 2020. [citado em 2020 mar 20]. Disponível em: https://www. saude.gov.br/noticias/agencia-saude/46540-saude-anunciaorientacoespara-evitar-a-disseminacao-do-coronavirus.

3. Governo Estado de São Paulo. Campanha de Utilidade Pública: Fique em Casa. [citado em 2020 abr 02]. Disponível em: https://www.youtube.com/watch?v=D2zESBXbauA.

4. Brasil. Ministério da Saúde. Coronavírus (Covid-19). Sobre a doença. 2020. [citado em 2020 abr 02].Disponível em:https:// coronavirus.saude.gov.br/sobre-a-doenca\#transmissao.

5. U.S. Department of Health and Human Services. Physical Activity Guidelines Advisory Committee Scientific Report PAGAC. Washington, DC: U.S. Department of Health and Human Services; 2018. [citado em 2020 jan 20]. Disponível em: https://health.gov/sites/default/files/2019-09/PAG_ Advisory_Committee_Report.pdf.

6. Brasil. Ministério da Saúde. Covid19. Painel Coronavírus. 2020. [citado em 2020 abr 01]. Disponível em: https://covid. saude.gov.br/.
7. Fragoso S, Recuero R, Amaral A. Métodos de pesquisa para a internet. Porto Alegre: Sulina, 2015.

8. Fisher RMB. Foucault e a análise do discurso em educação. Cad. Pesqui. [online] 2001;sv(n.114):197-223.

9. Foucault M. História da Sexualidade I - a vontade de saber. Rio de Janeiro: Edições Graal, 2010.

10. Foucault M. Nascimento da biopolítica: curso dado no Collège de France (1978-1979). São Paulo: Martins Fontes, 2008.

11. Bilibio LFS, Damico JGS. Carta a um jovem professor. Cad Formação RBCE. 2011;2(2):92-103.

12. World Health Organization/WHO. Regional office for Europe. Stay physically active during self-quarantine. 2020. [citado em 2020 abr 02]. Disponível em: http://www.euro. who.int/en/health-topics/health-emergencies/coronaviruscovid-19/novel-coronavirus-2019-ncov-technicalguidance/stay-physically-active-during-self-quarantine/_ recache\#article.

13. American College of Sports Medicine/ACSM. Staying Physically Active During the COVID-19 Pandemic. 2020. [citado em 2020 abr 02]. Disponível em: https:/www. acsm.org/read-research/newsroom/news-releases/newsdetail/2020/03/16/staying-physically-active-during-covid19-pandemic.

14. Brasil. Ministério da Saúde. Por que é importante manterse fisicamente ativo durante a pandemia de Covid-19? 2020. [citado em 2020 abr 01]. Disponível em: https:// www.inca.gov.br/publicacoes/material-para-web/porque-e-importante-manter-se-fisicamente-ativo-durantepandemia-de.

15. Chen P, Mao L, Nassis GP, Harmer P, Ainsworth BE, Li F. Coronavirus disease (COVID-19): The need to maintain regular physical activity while taking precautions. J Sport Health Sci. 2020;9:103-4.

16. Conselho Regional de Educação Física da $4^{\circ}$ Região/ CREF4/SP. COVID-19: Nota de Esclarecimento $n^{\circ} 1$. 2020. [citado em 2020 abr 02]. Disponível em: http://www. crefsp.gov.br/noticia/16330-COVID-19:-NOTA-DEESCLARECIMENTO-N\%C2\%B0-1.

17. Conselho Regional de Educação Física da Primeira Região/ CREF1/RJ-ES. Nota técnica do CREF1 sobre o coronavírus (COVID-19). [citado em 2020 abr 02]. Disponível em: https://cref1.org.br/informe/nota-tecnica-do-cref1-sobre-ocoronavirus/.

18. Simpson RJ, Campbell JP, Gleeson M, Krüger K, Nieman DC, Pyne DB, et al. Can exercise affect immune function to increase susceptibility to infection? Exerc Immunol Rev. 2020;26:8-22.

19. Zhu W. Should, and how can, exercise be done during a coronavirus outbreak? An interview with Dr. Jeffrey A. Woods. J Sport Health Sci. 2020;9:105-7.

20. Carvalho FFB. Recomendações de atividade física para a saúde (pública): reflexões em busca de novos horizontes. ABCS Health Sciences. 2019;44(2):131-7.

21. Programa das Nações Unidas para o Desenvolvimento/ PNUD. Relatório Nacional de Desenvolvimento Humano do Brasil - Movimento é vida: atividades físicas e esportivas para todas as pessoas: 2017. Brasília: PNUD, 2017.

22. Colégio Brasileiro de Ciências do Esporte - CBCE. Moção de Repúdio ao pronunciamento do presidente Bolsonaro sobre o Coronavírus. [citado em 2020 mar 29]. Disponível em: http://www.cbce.org.br/noticias-detalhe.php?id=1435. 
23. Brasil. Ministério da Saúde. Secretaria de Vigilância em Saúde. Departamento de Análise em Saúde e Vigilância de Doenças Não Transmissíveis. Vigitel Brasil 2019 [recurso eletrônico]. 2020.

24. Chignola S. Reinventar a liberdade, reinventar a si próprio. IHU On-Line: Revista do Instituto Humanitas Unisinos. 2015;472:20-5.

25. Peters M. Financeirização, o ácido que corrói a democracia. IHU On-Line: Revista do Instituto Humanitas Unisinos. 2015;472:26-32.

26. Abib LT, Gomes IM. A educação e o governamento dos corpos na atualidade: uma análise do "Movimento 21 dias por uma vida mais saudável”. Saude Soc. 2019; 28(4):229-42.

27. Foucault M. A Ordem do Discurso: aula inaugural no Collège de France pronunciada em 2 de dezembro de 1970. Trad. Laura Fraga Sampaio. 3º ed. São Paulo: Edições Loyola, 1996.
28. Foucault M. Do Governo dos Vivos: curso dado no Collège de France (1979-1980). São Paulo: Martins Fontes, 2014.

29. Caponi S. A saúde como objeto de reflexão filosófica. In: Bagrichevski M, Palma A, Estevão A (orgs). A saúde em debate na Educação Física. Blumenau: Edibes, 2003.

30. Brasil. Ministério da Saúde. Portaria GM N ${ }^{\circ} 2.446,11$ de novembro de 2014. Redefine a Política Nacional de Promoção da Saúde.

Recebido: 09/07/2020

Aprovado: 06/08/2020

\section{Como citar este artigo:}

Knuth AG, Carvalho FFB, Freitas DD. Discursos de instituiçôes de saúde brasileiras sobre atividade física no início da pandemia de COVID. Rev Bras Ativ Fis Saúde.2020;25:e0122. DOI: 10.12820/rbafs.25e0122 